\title{
DETECCIÓN DE ANIMALES PORTADORES DEL VIRUS DEL CÓLERA PORCINO EN UNA GRANJA TECNIFICADA DEL VALLE DE LIMA
}

\author{
Iván Camargo C. ${ }^{1}$, Hermelinda Rivera G. ${ }^{2}$ y Afredo Benito Z. ${ }^{2}$
}

\section{Abstract}

The objective of this study was to identify animal carriers of the Hog Cholera virus (HCV) post vaccination in a well-managed pig farm of Lima valley. A total of 166 serum samples were collected from 166 piglets between 6 and 7 weeks of age, vaccinated against Hog Cholera 15 days before sampling. Specific HCV antibodies were detected using a blocking ELISA test. Eighty eight (146/166) of animals reacted positively against HCV; $3 \%(5 / 166)$ and $9 \%(15 / 166)$ of animals were considered suspects and negatives to antibodies, respectively. A second sample was collected 30 days after the first collection from suspect $(n=5)$ and negative $(n=15)$ animals. HCV was detected by direct inmunofluorescence test using cultivated lymphocytes. At the time of the second sampling, 14 out of 20 animals stayed at farm. Antibodies were detected in 6 animals and 8 were negative, however 4 of the latter were positive to HCV. The results showed that the frequency of HCV carrier animals was $2.4 \%$ (4/166). The lack of antibodies and the presence of $\mathrm{HCV}$ in lymphocytes after vaccination, suggested that those animals were persistently infected and $\mathrm{HCV}$ carriers.

Key words: Hog cholera virus, antibody, antigen, carrier, blocking ELISA test

\section{Resumen}

El objetivo del presente estudio fue detectar animales portadores del virus del cólera porcino (VCP) luego de haber sido vacunados contra el cólera porcino (CP) en una granja tecnificada del valle de Lima. Se colectaron muestras de suero de 166 lechones de 7 a 9 semanas de edad y que fueron vacunados contra el Cólera Porcino 15 días antes del muestreo. La detección de anticuerpos contra el VCP se realizó mediante la prueba de ELISA de competición. Se obtuvieron muestras adicionales de los animales que resultaron negativos o dudosos a la prueba de ELISA a los 30 días posteriores al primer muestreo para la detección del VCP mediante la prueba de inmunofluorescencia en linfocitos cultivados. El 88\% (146/166) de los animales estudiados presentaron anticuerpos contra el VCP mientras que el $3 \%(5 / 166)$ y el $9 \%(15 / 166)$ de los animales presentaron resultados dudosos y negativos a anticuerpos, respectivamente. Catorce de los 20 animales negativos y dudosos pudieron ser muestreados a los 30 días del primer muestreo; de estos, 6 presentaron anticuerpos contra el VCP y 8 se mantuvieron negativos En el 50\% (4/8) de estos seronegativos se detectó el VCP. Estos resultados indican que la frecuencia de animales portadores del VCP en la granja estudiada fue de $2.4 \%(4 / 166)$. La falta de seroconversión frente a la vacunación y la presencia del VCP en linfocitos de estos animales sugieren que estos animales fueron inmunotolerantes y reservorios del VCP en la granja.

Palabras clave: Virus del Cólera Porcino, anticuerpos, antígenos, portador, ELISA de competición

\author{
${ }^{1}$ Práctica privada \\ ${ }^{2}$ Laboratorio de Microbiología y Parasitología, FMV-UNMSM. E-mail: hriverag@vet.unmsm.edu.pe
}




\section{INTRODUCCIÓN}

La crianza de porcinos en el Perú es una actividad mayoritariamente de autoconsumo, conservando un pequeño aunque importante componente tecnificado orientado al mercado. A pesar de que en el futuro inmediato no se avisora cambios significativos en las características de la producción porcina nacional, se espera que a largo plazo la crianza de autoconsumo cambie a una porcicultura tecnificada, orientada al mercado (Kalinowski, 2000). La porcicultura tecnificada en el país padece una crisis crónica de demanda como consecuencia del pobre consumo de carne de cerdo a nivel nacional $(3.7 \mathrm{Kg} / \mathrm{hab} / \mathrm{año}$, MINAG, 1999). Por esta razón se deberían buscar mercados externos donde los precios sean más aceptables, pero lamentablemente se tiene la barrera de las enfermedades infecciosas que se encuentran en la lista $A$ de la OIE, entre las que figura el cólera porcino (CP).

La enfermedad del cólera porcino es producida por el virus del cólera porcino(VCP), que conjutamente con los virus de la diarrea viral bovina (DVB) y enfermedad de la frontera, que afectan al bovino y ovino, pertenecen al género pestivirus de la familia Flaviviridae (Thiel et al., 1991). Como todos los pestivirus, el VCP posee cepas de diversos grados de virulencia, y que son agrupadas en biotipos citopatogénicos (CP) y no citopatogénicos (NCP) basados en su habilidad de producir lesión en cultivos celulares, siendo la mayoría de las cepas de campo del VCP biotipo NCP (Rumenapf et al., 1991; Bruschke et al., 1998).

En el Perú la enfermedad es endémica y, a pesar de los esfuerzos realizados para su control, continúa siendo un factor limitante para el desarrollo de la industria porcina tecnificada. Clínicamente puede ser de tipo agudo, crónico o subclínico, dependiendo del grado de virulencia de la cepa infectante. En los últimos tiempos, se viene observando que el cólera porcino subclínico es el más prevalente en las granjas tecnificadas (Rivera et al., 1999), causando infecciones transplacentarias y predisponiendo a los le- chones de engorde a infecciones subclínicas. La infección con cepas de baja virulencia en una marrana gestante puede pasar inadvertida; sin embargo, los lechones nacidos vivos pueden ser portadores del virus. Muchos de estos mueren poco después del nacimiento, en tanto que los sobrevivientes eliminan el virus por sus secreciones, contribuyendo a la endemia de la enfermedad.

Actualmente, la principal medida de control de los pestivirus está basada en la detección y eliminación de los reservorios o portadores mediante técnicas serológicas. El presente estudio tuvo como objetivo determinar la presencia de animales portadores del virus del cólera porcino en una granja tecnificada del valle de Lima, mediante la técnica de ELISA de competición, contribuyendo así a un mejor conocimiento de la epidemiología y al control del cólera porcino en el país.

\section{Materiales y Métodos}

\section{Localidad y animales}

El muestreo se realizó entre los meses de setiembre y noviembre del año 2000 , en una granja porcina tecnificada ubicada al sur del valle de Lima, con una población de 1,241 animales y 150 marranas en producción. Se trabajó con 166 lechones de 6 a 7 semanas de edad, de apariencia normal y de diferentes razas y sexos, vacunados 15 días antes contra el cólera porcino.

\section{Población muestral}

El tamaño mínimo de muestra poblacional $(n=84)$ fue obtenido aplicando el método de muestreo de prevalencia límite (Ahlbom y Norell, 1990), tomándose como referencia una prevalencia de $3.5 \%$ de animales persistentemente infectados, según trabajos previos (H. Rivera, comunicación personal) y un nivel de confianza del $95 \%$. Sin embargo se trabajó 166 lechones para una mejor confiabilidad de los resultados. 


\section{Recolección y análisis de muestras}

Las muestras fueron obtenidas por punción de la vena cava, mediante agujas y tubos al vacío (vacutainer), a los 15 y 45 días postvacunación. Las muestras de sangre debidamente identificadas, fueron transportadas al Laboratorio de Virología de la Facultad de Medicina Veterinaria de la Universidad Nacional Mayor de San Marcos, para su procesamiento, almacenamiento a $-20^{\circ} \mathrm{C}$ y análisis. La detección de anticuerpos contra el VCP se realizó mediante la prueba de ELISA de competición o bloqueo, y utilizando un kit comercial (Synbiotics, USA),

Las muestras de suero que presentaron un porcentaje de inhibición o bloqueo de 40 a $100 \%$ fueron consideradas positivas a anticuerpos contra el VCP. Aquellas con $<30 \%$ de inhibición se consideraron negativas y aquellas que presentaron entre $30 \mathrm{y}$ $40 \%$ de inhibición se consideraron dudosas. A los animales con resultados negativos o dudosos se les tomó una segunda muestra a los 45 días postvacunación, conjuntamente con una muestra de sangre con anticoagulante (EDTA) para el cultivo de linfocitos y detección del VCP.

Se consideró que si existe al menos un animal positivo, se podría concluir que la prevalencia de animales inmunotolerantes es de al menos 3.5\% (prevalencia límite). En cambio, si no existen animales positivos, se consideraría que no existen animales inmunotolerantes o su prevalencia está por debajo de la prevalencia límite.

\section{Resultados}

El $88 \pm 4.9 \%(146 / 166)$ de las muestras presentaron anticuerpos con 40 a $100 \%$ de inhibición a los 15 días posteriores a la vacunación contra el VCP. Un $3 \pm 2.6 \%$ (5/ 166) mostraron 30 a $40 \%$ de inhibición y $9 \pm$ $4.4 \%(15 / 166)$ tuvieron menos de $30 \%$ de inhibición, considerándose dudosas y negativas, respectivamente.
Sólo se pudo volver a tomar muestras a 14 de los 20 animales que salieron con resultados dudosos (5) y negativos (15), ya que 6 habían sido eliminados de la granja por diversos problemas sanitarios. De estos, $6(42.9$ $\pm 6.8 \%$ ) presentaron anticuerpos contra el virus. El cultivo de linfocitos de los 8 animales seronegativos mostró que el $50 \pm 35 \%$ (4/ 8 ) estuvieron infectados con el virus del VCP, permitiendo concluir que la frecuencia de animales portadores del virus VCP en la granja estudiada fue de $2.4 \pm 2.3 \%$ (4/166).

\section{Discusión}

La granja en estudio posee un programa de vacunación contra el cólera porcino donde los lechones son vacunados a los 45 días de edad. Como consecuencia de la vacunación los animales deben desarrollar anticuerpos neutralizantes o protectores contra el virus de campo y este supuesto, si bien es asumido por todos los porcicultores y veterinarios de campo, no se han realizado estudios de monitoreo de respuesta. En el presente trabajo se planteó la hipótesis de que existen porcinos que no presentan anticuerpos contra el VCP post vacunación, el mismo que ha sido demostrado en el estudio y que explica en parte la endemia de esta enfermedad en las granjas porcinas, pese al uso de programas de vacunación.

Una seroconversión postvacunación contra el cólera porcino en el $88 \%$ de los animales con porcentajes de inhibición de más del $40 \%$ indica que el virus es uno de los mejores inmunógenos en el campo de la medicina veterinaria (Dahle y Liess, 1995). Países como USA, Canadá, Australia y otros lograron erradicar el cólera porcino utilizando la vacuna clásica (Foreing Animal Diseases, 1998). Los ocho animales con resultados dudosos y negativos pudieron deberse al tiempo de colección de las muestras (15 días post vacunación) ya que en algunos animales la seroconversión inicial puede ser lenta (Oirschot, 1980). Existen informaciones que indican que la variación antigénica en caso 
del VCP es limitada para interferir significativamente con la eficacia de las vacunas vivas modificadas (Paton, 1995).

La ausencia de anticuerpos y la presencia de virus en 4 animales del estudio indica que fueron persistentemente infectados e inmunotolerantes al virus por lo que no habrían sido capaces de seroconvertir como el resto de animales constituyendo un fuerte argumento a favor de que la infección tuvo lugardurante la etapa prenatal. Por otro lado, la ausencia de anticuerpos y virus en otros cuatro lechones pudo deberse a que estos animales no fueron inmunizados ni expuestos al VCP. Es poco probable que los niveles de anticuerpos y de virus fueran muy pequeños para ser detectados ya que el ELISA utilizado tiene una sensibilidad superior al $99 \%$. Estos animales sin anticuerpos posiblemente son también susceptibles de infectarse en cualquier momento mientras estén en la granja. En el caso de los pestivirus, la inmunotolerancia es establecida cuando la marrana es infectada por una cepa NCP y/o de baja virulencia durante el primer tercio de la gestación (Bruschke et al., 1998). Igualmente, ha sido ampliamente demostrado que el principal mecanismo de persistencia de los pestivirus es su capacidad de atravesar la placenta y establecer la infección persistente y la inmunotolerancia en la cría y que estos animales son esenciales para la sobrevivencia y mantenimiento del virus en la granja o hato (Nettleton y Entrican, 1995).

Estudios previos realizados en nuestro medio han demostrado la existencia de porcinos persistentemente infectados procedentes de granjas tecnificadas y no tecnificadas mediante la detección del antígeno viral en tejidos porcinos con problemas distintos al cólera porcino agudo, sugiriendo la existencia de cepas de baja virulencia y que son mantenidas en las granjas a pesar de la vacunación; aunque en esos estudios no se evaluó la presencia de anticuerpos contra el VCP (Rivera et al.,
1999). Uno de los mecanismos que permitiría la sobrevivencia viral en algunas granjas, tal vez favorecidas por un inadecuado sistema de manejo podría ser a través de animales portadores como los que se han detectado en el presente estudio.

A diferencia del pestivirus bovino (el VDVB), donde el animal portador permanece en esta condición durante toda su vida, en el porcino la persistencia viral está aparentemente limitada a pocas semanas o meses, después del cual el animal muere con signos del cólera porcino crónico o por infecciones secundarias. Van Oirschot (1980) refiere haber mantenido porcinos persistentemente infectados hasta por 11 meses. Sin embargo, el VCP tiene posibilidades de sobrevivir en la granja gracias a la continua renovación de poblaciones de animales susceptibles. El $2.4 \%$ de porcinos del estudio, que fueron vacunados contra el VCP pero que resultaron con ausencia de anticuerpos y con presencia de virus en su organismo, constituiría fuente suficiente de virus para mantener la infección en la granja.

En el caso de la granja en estudio no se observó casos clínicos de cólera porcino agudo, pero los problemas respiratorios y diarreicos fueron frecuentes, y posiblemente el principal rol de la(s) cepa(s) del VCP que circula en la granja es la de un agente inmunodepresor y condicionante a infecciones secundarias del tracto respiratorio $y / o$ digestivo.

Los resultados del presente estudio demuestran que existen animales que no seroconvierten luego de la vacunación, y que poseen el virus en su organismo, por lo que se hace necesario realizar el monitoreo de la vacunación contra el cólera porcino. La detección y eliminación de los animales que no seroconvierten, más la inmunización y una buena bioseguridad deben ser medidas fundamentales para un efectivo control y erradicación del cólera porcino, por lo menos en las granjas porcinas tecnificadas del país. 


\section{Conclusiones}

- Existen animales que no desarrollan anticuerpos contra el cólera porcino postvacunación, y animales que no poseen anticuerpos ni virus del cólera porcino postvacunación.

- Existen animales que no poseen anticuerpos y que poseen el virus del cólera porcino indicando que estos animales son inmunotolerantes y portadores del virus en la granja en estudio.

\section{Literatlra Citada}

1. Ahlbom, A; S. Norel. 1990. Introduction to modern epidemiology. $2^{\text {th }}$ ed., $p$ 24-29. Epidemiology Resources Inc. USA.

2. Brudchke, C.J.M; A. Haghparast; A. Hoek; V.P. Rutten; G.H. Wentink; P.A. Van Rijn; J.T. Van-Oirschot. 1998. The immune response of cattle persistently infected with noncytopathic BVDV after superinfection with antigenically semihomologous cytopathic BVDV. Vet. Immunol. Immunopathol. 62: 37-50.

3. Dahle J.; B. Liess. 1995. Assessment of safety and protective value of a cell culture modified strain " $C$ " vaccine of hog cholera/classical swine fever virus. Beirl. Munch. Tierarztl. Wschr. 108: 20-25.
4. Foreign Animal Diseases. Committee for Foreign Animal Diseases of the United States Animal Health Association. 1998. Pat Campbell \& Associates and Carter Printing Company Richmond, Virginia, USA. p 275-282.

5. Kalinowski, J. 2000. Situación de la porcicultura nacional: Análisis y perspectivas. II Congreso Nacional de Porcicultura y Expo porcina. Lima-Perú. Resumen: 1-10.

6. Minag-OIA. 1999. Producción pecuaria e industria avícola. Oficina de Información agraria. Boletín informativo.

7. Nettleton, P.; G. Entrican. 1995. Ruminant pestivirus. Br. Vet. J. 151: 615642.

8. Paton, D.J. 1995. Pestivirus diversity. J. Comp. Pathol. 112: 215-236.

9. Rivera H.; R. Angeles; N. Sandoval; A. Manchego. 1999. Persistencia del virus del cólera porcino de baja virulencia en el sistema nervioso central de lechones de granjas tecnificadas. Rev. Inv. Vet. 10: $1-10$.

10. Rümenapf, T.; G. Meyers; R. Stark; HJ. Thiel. 1991. Molecular characterization of hog cholera virus. Arch. Virol. Suppl 3: 7-18.

11. Van Oirschot, J.T. 1980. Persistent and vinaparent infections with swine fever virus of low virulence. Their effects on the immune system. Thesis, State Univ Utrecht. Netherlands. 